\title{
Bringing a Multidisciplinary Perspective of IT to the Classroom: A Theory-Based Development of a Second Course for Non-Majors
}

\author{
Ned Kock, Robert Aiken, and Cheryl Sandas \\ Temple University, Philadelphia, PA, USA
}

kock@sbm.temple.edu alken@oda.cis.temple.edu csandas@bellatlantic.net

\section{Executive Summary}

IT instructors in information systems and computer science departments are often the target of complaints from colleagues in other disciplines who argue that students need to see how IT is applied in their own specific disciplines. We try to address these complaints by devising a course where IT concepts are taught from the perspective of different disciplines. The course presents IT concepts through case studies of complex and specialized IT systems that are used to solve problems in well-defined domains. A pilot implementation of the course is analyzed, with three case studies in anthropology, sociology and chemistry.

The analysis suggests that the case studies had a positive impact on how students, who are not particularly interested in IT, perceive IT in general, and its application to complex and specialized tasks. While the students generally perceived that they learned from the case studies, the results also suggest that the case studies did not have a positive impact on the students' willingness to pursue an IT career or take other IT courses. One plausible explanation for this, based in part on GOMS theory (Card et al., 1983) and cognitive flexibility theory (Spiro and Jehng, 1990; Spiro et al., 1992), is that subjecting non-majors to complex and specialized IT applications increases their "respect" for IT's potential, but does not help them gain confidence about being specialized IT users themselves. It is quite possible that the degree of technological and domain complexity in the case studies led the students to believe that using IT was too difficult for the tasks that they may have to accomplish in their chosen fields of study.

Several of the negative student perceptions were in connection with the relevance of this type of course for their chosen major or career. These perceptions are consistent with the principles of meaningfulness from minimalist theory (Carroll, 1990; 1998) and immediate relevance from andragogy theory (Knowles, 1975; 1984, 1984b), and suggest that this type of course may not be appropriate as a "core" (i.e., non-elective) course. Some computer problems occurred due to the complexity of the anthropology and chemistry computer systems and related installation problems, which should be easy to resolve in future course offerings. Also, the perceived complexity of the topics can be addressed by dedicating more time to the demonstration of the computer systems and how they relate to the concepts and theory

Material published as part of this journal, either on-line or in print, is copyrighted by the publisher of the Journal of Information Technology Education. Permission to make digital or paper copy of part or all of these works for personal or classroom use is granted without fee provided that the copies are not made or distributed for profit or commercial advantage AND that copies 1) bear this notice in full and 2) give the full citation on the first page. It is permissible to abstract these works so long as credit is given. To copy in all other cases or to republish or to post on a server or to redistribute to lists requires specific permission and payment of a fee. Contact Editor@JITE.org to request redistribution permission. discussed in the lectures.

The development of new domain-specific case studies is an important area of further research in connection with this study. One area in which problems may arise is when the views of the domain experts about what is an interesting (or even acceptable) topic may not match the views of the students. For example, a student majoring in anthropology may see a case study on computer ap- 
plications in molecular biology research as too "dry" or specialized to be meaningful.

Keywords: Information Systems, Information Technology Education, Lifelong Learning, Fluency in Information Technology.

\section{Introduction}

Information technology (IT) is central to modern society (Toffler and Toffler, 1995). Moreover, its use and technical development are increasing rapidly (Khosrwopour, 1998; Laudon and Laudon, 1999). However, it has been shown that learning to use IT effectively in individual and organizational domainspecific processes cannot be done in a single step (Spiro and Jehng, 1990; Spiro et al., 1992). It requires appropriate introductory concepts, experiences, and motivations, and a life-long commitment to learning (Knowles, 1975; 1984, 1984b). This paper describes our approach for developing a second level course that provides a strong foundation in IT that is embedded in hands-on use of the technology in different complex, research and information-rich environments for students who are not information systems or computer science majors. Our approach is centered on the development of complex and domain-specific case studies, which are used as the main delivery method in a second IT course for non-majors. In this paper we outline the process and rationale that guided the development of case studies, assessment procedures, and the results of a pilot implementation of three case studies of IT use in anthropology, sociology and chemistry.

Students who participated in this study were drawn from three different sections of a course in computer literacy that was designed for non-computer and information science majors. Students in this course were primarily sophomores, and in this study about $60 \%$ were males. Each of the three sections was given a different case study with the presenter (from the relevant subject area) being assisted by the class instructor.

This paper is organized as follows. First, we review theories of IT education, and then we examine current course and curriculum development initiatives, and explain how our project differs from those initiatives. Next we discuss the design of the course, showing which theoretical principles were implemented in the course. Building on this, we discuss a pilot evaluation of the course from both quantitative and qualitative perspectives. We conclude with a discussion of the quantitative and qualitative analyses performed in the previous section vis-à-vis our previous discussion of theoretical considerations. This section also identifies future research opportunities and challenges.

\section{Theoretical Considerations}

The increasing utilization of IT in organizations and society has led to the emergence of IT-related learning as a separate and important area of education research. Several theories have been developed, particularly since the 1970s, to explain, predict and help design IT learning materials, courses and curricula, as well as use IT to teach other subjects. These theories include conversation theory (Pask, 1975), symbol systems theory (Salomon, 1979; 1981; Salomon et al., 1991), GOMS theory (Card et al., 1983), programming-facilitated learning theory (Papert, 1980; 1993), cognitive flexibility theory (Spiro and Jehng, 1990; Spiro et al., 1992), minimalist theory (Carroll, 1990; 1998), and andragogy theory (Knowles, $1975 ; 1984,1984 \mathrm{~b})$. These theories provide important insights into the problems and opportunities associated with teaching IT and using IT to teach other subjects. A brief summary of these theories is provided in Table 1, which leaves out the last two theories, namely minimalist theory (Carroll, 1990; 1998) and andragogy theory (Knowles, 1975; 1984, 1984b), from which key principles are implemented in our course. These two theories are reviewed separately and in more detail below with an emphasis on key principles of each theory. 


\begin{tabular}{|c|c|c|}
\hline Theory & Description & References \\
\hline $\begin{array}{l}\text { Conversation } \\
\text { theory }\end{array}$ & $\begin{array}{l}\text { Argues that IT learning occurs through conversations about IT in the context } \\
\text { of a subject matter and that these conversations serve to make knowledge ex- } \\
\text { plicit. }\end{array}$ & Pask, 1975 \\
\hline $\begin{array}{l}\text { Symbol systems } \\
\text { theory }\end{array}$ & $\begin{array}{l}\text { Argues that different communication media involve different levels of process- } \\
\text { ing when used to convey subject matter content. For example, the theory sug- } \\
\text { gests that watching television requires less mental processing than reading a } \\
\text { book, and that thus the mental schemas developed through the former are less } \\
\text { elaborate than those developed through the latter. }\end{array}$ & $\begin{array}{l}\text { Salomon, } \\
1979 ; 1981 \\
\text { Salomon et } \\
\text { al., } 1991\end{array}$ \\
\hline GOMS theory & $\begin{array}{l}\text { Focuses on the cognitive skills required for human-computer interaction. } \\
\text { GOMS stands for goals, operators, methods and selection rules, which make } \\
\text { up the four main components of the theory. }\end{array}$ & $\begin{array}{l}\text { Card et al., } \\
1983\end{array}$ \\
\hline $\begin{array}{l}\text { Programming- } \\
\text { facilitated learn- } \\
\text { ing theory }\end{array}$ & $\begin{array}{l}\text { Argues that children can better understand concepts in a variety of domains, } \\
\text { including mathematics, if they are able to operationalize those concepts } \\
\text { through writing computer programs. }\end{array}$ & $\begin{array}{l}\text { Papert, 1980; } \\
1993\end{array}$ \\
\hline $\begin{array}{l}\text { Cognitive flexi- } \\
\text { bility theory }\end{array}$ & $\begin{array}{l}\text { Focuses on the nature of learning in complex and ill-structured domains and is } \\
\text { largely concerned with the transfer of IT knowledge and skills beyond their } \\
\text { initial learning situation. }\end{array}$ & $\begin{array}{l}\text { Spiro and } \\
\text { Jehng, 1990; } \\
\text { Spiro et al., } \\
1992\end{array}$ \\
\hline
\end{tabular}

\section{Table 1: Main IT learning theories}

Carroll $(1990 ; 1998)$ developed the minimalist theory, which is a general theory of IT education that places particular emphasis on principles for the design of IT instruction materials (Van Der Meij and Carroll, 1995). The theory proposes five main principles for IT education: meaningfulness, application, improvisation, recovery and realism. The principle of meaningfulness states that all IT learning tasks should be self-contained and meaningful to the learners. The principle of application states that learners should be given realistic IT projects as soon as possible in their learning curve. The principle of improvisation states that IT instruction should permit self-directed reasoning and improvising. The principle of recovery states that IT training materials and activities should allow for error recognition and recovery. Finally, the principle of realism states that there should be a close linkage between the training and the actual use of the system.

Knowles's $(1975 ; 1984,1984 b)$ theory of andragogy places particular emphasis on adult learning of IT. The theory highlights the fact that adults are self-directed and expect to take a proactive role in and responsibility for IT learning decisions. Andragogy theory advocates that IT instruction for adults needs to focus more on the process and less on the content being taught. It points out that strategies such as case studies, role-playing, simulations, and self-evaluation are useful in achieving this goal. Andragogy theory espouses the notion that instructors should adopt the role of facilitators rather than those of lecturers or graders. Andragogy theory can be summarized through four main principles: design involvement, experiential learning, immediate relevance, and problem solving. The principle of design involvement states that adults need to be involved in the planning and evaluation of their IT instruction. The principle of experiential learning states practical experience, including mistakes, should provide the basis for IT learning activities. The principle of immediate relevance states that adults are most interested in, and thus learn more efficiently, IT subjects that have immediate relevance to their job or personal life. The 
principle of problem solving states that effective adult IT learning is problem-centered rather than content-oriented.

Our second IT course for non-majors aims at providing a strong foundation in IT that is embedded in hands-on-use of the technology in different complex, research and information-rich environments. These key goals call for the implementation of a subset of the theoretical principles discussed above. We specifically implement, in a first step, the principles of application and realism from Carroll's (1990; 1998) minimalist theory, and the principles of experiential learning and problem solving from Knowles's $(1975 ; 1984,1984 b)$ theory of andragogy. The implementation of these principles is discussed later in the paper. A discussion of how the implementation of other theoretical principles, which would require an expanded set of goals for our course, would likely affect the outcomes of the course is provided at the end of the paper, along with challenges to be addressed in further research.

\section{Current Course and Curriculum Development Initiatives}

It is useful to look at funded projects in order to identify key curriculum development initiatives. For example, by reviewing the projects in course and curriculum development supported by the National Science Foundation (NSF) in the US, one can see the depth of concern and the extent and variety of efforts addressing the problem of teaching IT to non-majors. Listed below, in Table 2, are some representative approaches to the introductory and second level IT courses for non-majors.

The current interest in innovative approaches for IT teaching to non-majors can also be drawn from the recent literature on IT education, such as the studies by Gurwitz (1998), Joyce (1998), Schneider (1999) and Marks et al. (2001). Gurwitz (1998) uses the Internet as a motivating theme of a computer literacy course for non-majors. We differ in that we try to provide a more advanced understanding of IT concepts and application, beyond the scope of computer literacy courses. Joyce (1998), for example, uses a case building approach in which students learn through writing an essay about how an individual (the main subject of their essay) uses a computer to solve a specific problem. We differ in that several cases are analyzed in one course, each prepared by an expert in the field and involving actual hands-on use of the computer tool used by the expert. Schneider (1999) uses a course in computational science as a bridge between science disciplines particularly physical and natural sciences. We differ in that we are not restricted to a specific group of non-majors. For example, we assume that our students already have some basic knowledge about word processing and spreadsheet tools as well as Internet-related skills, which they should have acquired from a basic level computer literacy course. Marks et al. (2001) developed a computer applications course that incorporates case studies for an adult education context. Their approach is similar to ours. Moreover, we agree with their observation that their course " ... can be modified to serve as an alternative introductory course for non-majors." (p. 84) However, their case studies are all drawn from areas within computer science whereas we emphasize case studies that are drawn from the disciplines of our three non-computer science lecturers. We believe that "grounding" these case studies in different subjects will better motivate students and help convince them of the wide ranging versatility of this ubiquitous tool. This is a key for them to not only become computer fluent but to stay current with technology long after they finish this course.

We should also note that interest has continued since we first began discussing our ideas for developing a course in computer fluency. For example, a colleague from Haverford College, Dr. John Dougherty, is organizing a working group on IT fluency for the ACM2002 ITiCSE conference as a follow-up to a session he organized at the ACM SIGCSE Technical Symposium in 2001 (additional information is available at: http://WWW.cs.haverford.edu/ITfluency/. Thus, a lot of interest exists in developing and implementing computer fluency courses similar to the prototype discussed in this paper. 
Portable Courseware for Technological Literacy (DUE 7419) B. Fagin - Dartmouth College, Hanover, New Hampshire.

This project shares some of our goals (some quotes from the proposal): “... to reach students who would not normally consider technologically oriented courses, the course ... will require no mathematics." "The course will use a handson, active approach to learning." We differ in the problems being considered. We are stressing the use of a few, well developed, domain-specific problems, presented and motivated by domain experts, rather than a multiplicity of "toy" problems. The media used in our two projects are different. The Dartmouth group has worked on development of a CD-ROM. We will make our material available on the Web.

Laboratory for Great Ideas in Computer Science (DUE 7400) J. Howland and G.Pitts - Trinity University, San Antonio, Texas.

Though aimed at a similar student population, their proposal, partially quoted next, differs substantially from ours: "This new course concept implements a contained laboratory that uses a breadth first rather than depth first approach to cover a broad range of computer science topics at the introductory level." We are not aiming for coverage of many topics, we are aiming for few topics, to be experienced in a rich motivating environment.

A second Course in Computing for Non-Majors (DUE 7410) J. Waxman - Queens College, CUNY, New York.

Here, what is proposed is "... a second course which focuses on the acquisition and presentation of data and information. For data acquisition, the course gives the student high level mastery of the Internet. For the presentation of information students will master a multimedia authoring system..." Our interest is less with the tools and more on their role in problem solving as demonstrated by case studies and in student projects. We believe that IT is used not just because "it is there", and for what "it might do", but because students experience how to use it to become successful problem solvers.

\section{Table 2: Representative approaches to the introductory and second level IT courses for non-majors funded by the NSF}

\section{Course Design}

From a theoretical perspective, our approach to teaching IT implements the principles of application and realism from Carroll's $(1990 ; 1998)$ minimalist theory. The case studies employ realistic IT projects that closely tie training with the actual use of the system. Our approach also implements the principles of experiential learning and problem solving from Knowles's $(1975 ; 1984,1984 b)$ theory of andragogy. We emphasize the solution of practical problems in specific domains in our course and adopt a problemcentered rather than content-oriented approach to IT learning.

The course uses a case study approach to lead students through the solution of substantial problems that integrate domain-specific knowledge and logic, general scientific problem-solving strategies, IT and mathematical methods, and coordinated use of a number of IT tools. Students see how professionals from specific disciplines use IT to solve complex problems. Those professionals explain the domain knowledge and logic and together with the IT faculty discuss the process by which IT is deployed. The goal is to help students become personally involved in IT-supported problem solving as active learners, almost as if they were members of the project teams examined in the case studies. Students work on lab projects to adapt the methods and software used in case studies to solve real world problems in specific disciplines.

Complementing the case studies are modules describing salient aspects of IT. These modules establish the conceptual and technological context within which applications and continued learning will take 
place. Where the first IT course for non-majors provides the foundations for students to use basic IT tools and concepts, our second IT course helps students use IT in their problem-solving at the level required by higher level discipline-specific courses. Thus such courses can focus on discipline content instead of repeatedly worrying about developing IT skills.

More specifically, professionals from chemistry, anthropology and sociology were selected based on their use of IT in their respective disciplines. These professionals created domain specific IT case studies derived from real research problems. Since the main criteria for the case studies is that professionals use IT to solve discipline specific complex problems, the current case studies could be easily replaced by case studies from other disciplines. Each case study is presented to the students over a period of two weeks. Each week consists of two lectures and one lab to provide the students with background information for the case study as well as hands-on exposure to the IT involved in the case. The students are given an assignment to complete by the end of each case study to demonstrate their understanding of the case and knowledge of the associated IT.

This is a fourteen-week course that alternates every two weeks between IT modules and the case studies. In addition, the first week is used as an introduction and overview of different topics that will be covered. The final week is reserved for students to present their projects. The IT modules follow the same format and are taught by either information technology or computer science faculty.

The course culminates with a final project, demonstrating the synthesis of some of the concepts covered during the semester. Additional information about the course, including course materials, slides, and assignments, can be found at http://Ww2.cis.temple.edu/nsflII//(three small letter "l"s follow "nsf").

\section{Assessing a Pilot Implementation of the Course}

A pilot implementation of the course was conducted with students of an introductory course on IT. This course is a typical "computer literacy" course covering topics such as Microsoft Office and basics of using the World Wide Web. The pilot implementation was conducted at the end of the introductory course so that the students would already have learned basic IT skills that come from taking a computer literacy course. The three case studies described in Appendix A (in anthropology, sociology and chemistry) were taught in three different sections of the introductory course. After each case study, students were asked to complete the questionnaire in Appendix B, which contains multiple choice and open-ended questions. Below, we summarize the results of the analysis of this research data, which have also been discussed in a previous paper (Kock et al., 2002).

Table 3 summarizes the quantitative answers from the questionnaire in Appendix B, separated by application area. They suggest that students, on average, did not have a good knowledge of IT (Q1), were not particularly interested in taking IT courses $(\mathrm{Q} 2)$, and were not generally attracted to IT (Q3) prior to taking the course and working through the cases.

Regarding the impact of the case studies on students' IT perceptions, the answers suggest that the case studies: did not have a positive influence on their perception that they should take more IT courses in the future (Q4); did not have a positive influence on their perception that they should pursue an IT career (Q5); had a positive influence on their perception of IT's potential for solving complex tasks (Q6); and had a positive influence on their general perception of IT (Q7). The compilation of answers in Table 3 also suggests that students, in general, perceived that they learned something but not much about specialized IT applications (Q8) and IT issues in general (Q9).

Table 4 summarizes the results of a correlation analysis of the quantitative answers provided for questions Q1 to Q9. The quantitative answers were given based on a Likert scale (see Appendix B), and the analysis technique used was Spearman's (a nonparametric technique - see, e.g., Siegel and Castellan, 
Kock, Aiken, \& Sandas

\begin{tabular}{|c|c|c|c|c|}
\hline & $\begin{array}{c}\text { Anthropology } \\
(\mathrm{N}=12)\end{array}$ & $\begin{array}{c}\text { Sociology } \\
(\mathrm{N}=18)\end{array}$ & $\begin{array}{c}\text { Chemistry } \\
(\mathrm{N}=14)\end{array}$ & Mean \\
\hline $\begin{array}{l}\text { Q1. I already had a very good knowledge of Information } \\
\text { Technology (IT) prior to taking this course. }\end{array}$ & 2.08 & 2.06 & 1.50 & 1.88 \\
\hline $\begin{array}{l}\text { Q2. I intended to take as many IT courses as possible in } \\
\text { college prior to taking this course. }\end{array}$ & 1.33 & 1.44 & 1.36 & 1.38 \\
\hline $\begin{array}{l}\text { Q3. I was generally very attracted to IT issues prior to } \\
\text { taking this course. }\end{array}$ & 1.33 & 1.53 & 1.64 & 1.50 \\
\hline $\begin{array}{l}\text { Q4. The case study made me feel like I should take more IT } \\
\text { courses in the future, even if I don't pursue a career in IT. }\end{array}$ & 1.75 & 1.94 & 1.93 & 1.87 \\
\hline $\begin{array}{l}\text { Q5. The case study made me feel like I should pursue an IT } \\
\text { career. }\end{array}$ & 0.75 & 1.22 & 0.93 & 0.97 \\
\hline $\begin{array}{l}\text { Q6. The case study improved my perception of IT's } \\
\text { potential for solving complex tasks. }\end{array}$ & 2.58 & 2.44 & 2.92 & 2.65 \\
\hline Q7. The case study improved my general perception of IT. & 2.58 & 2.39 & 2.77 & 2.58 \\
\hline $\begin{array}{l}\text { Q8. I learned a lot from this case study about specialized IT } \\
\text { applications. }\end{array}$ & 2.20 & 2.17 & 2.31 & 2.22 \\
\hline $\begin{array}{l}\text { Q9. I learned a lot from this case study about IT issues in } \\
\text { general. }\end{array}$ & 2.00 & 2.44 & 1.92 & 2.12 \\
\hline
\end{tabular}

Range: 0 - 4 (Mid scale = 2)

Table 3: Summary of quantitative answers

\begin{tabular}{|c|c|c|c|}
\hline & $\begin{array}{l}\text { Anthropology } \\
(\mathrm{N}=12)\end{array}$ & $\begin{array}{c}\text { Sociology } \\
(\mathrm{N}=18)\end{array}$ & $\begin{array}{c}\text { Chemistry } \\
(\mathrm{N}=14)\end{array}$ \\
\hline $\begin{array}{l}\text { Q4. The case study made me feel like I should take more IT } \\
\text { courses in the future, even if I don't pursue a career in IT. }\end{array}$ & & Q2,Q3 & Q6 \\
\hline $\begin{array}{l}\text { Q5. The case study made me feel like I should pursue an IT } \\
\text { career. }\end{array}$ & Q2,Q3 & & Q2 \\
\hline $\begin{array}{l}\text { Q6. The case study improved my perception of IT's } \\
\text { potential for solving complex tasks. }\end{array}$ & & & Q4 \\
\hline
\end{tabular}

Q7. The case study improved my general perception of IT.

Q8. I learned a lot from this case study about specialized IT applications.

Q9

Q9. I learned a lot from this case study about IT issues in general.

$P<.01$ and Coeficient $>.6$

Q1. I already had a very good knowledge of Information Technology (IT) prior to taking this course.

Q2. I intended to take as many IT courses as possible in college prior to taking this course.

Q3. I was generally very attracted to IT issues prior to taking this course.

\section{Table 4: Significant correlation coefficients}

\section{(See Appendix C for full correlation tables)}

1998). The coefficients were calculated based on a two-tailed test. Full correlation tables with actual coefficients, number of cases and "sigmas" are provided in Appendix C.

In Table 4, we focus on the relationship among variables Q4 to Q9, which refer to the impact of the case study on students, and between variables Q4 to Q9 and variables Q1 to Q3, which describe student perceptions about IT prior to taking the course and the case study. The correlation links indicated in Table 4 are those with chance probability lower than 1 percent (i.e., $P<.01$ ). They suggest that:

- In the sociology application, the impact of the case study on the students' perception that they should take more IT courses in the future (Q4) was significantly correlated with their predisposition to take IT courses $(\mathrm{Q} 2)$ and with how attracted they were to IT issues prior to taking the course (Q3).

- In the chemistry application, the impact of the case study on the students' perception that they should take more IT courses in the future (Q4) was significantly correlated with their perception of IT's potential for solving complex tasks (Q6). 
- In the anthropology application, the impact of the case study on the students' perception that they should pursue an IT career (Q5) was significantly correlated with their predisposition to take IT courses $(\mathrm{Q} 2)$ and with how attracted they were to IT issues prior to taking the course $(\mathrm{Q} 3)$.

- In the chemistry application, the impact of the case study on the students' perception that that they should pursue an IT career (Q5) was significantly correlated with their predisposition to take IT courses $(\mathrm{Q} 2)$.

- In the anthropology application, the impact of the case study on the students' perception of the degree to which they had learned something about specialized IT applications (Q8) was significantly correlated with the impact of the case study on the students perception of the degree to which they had learned something about IT issues in general (Q9).

The main sources of qualitative data in this study were the open-ended questions in the questionnaire distributed to students (available in Appendix B), participant observation notes taken by one teaching assistant and one researcher during each case, notes based on the focus group discussion involving one researcher and the students at the end of each case, and the instructor's own participant observation perceptions. The triangulation of the data coming from these different sources suggests positive and negative aspects of each case, which are summarized in Table 5.

An analysis of Table 5 suggests that the case studies had a positive impact on students' perceptions about IT's potential for supporting specialized tasks (PA1, PA2, PS1, PS2, PC1). However, they evoked negative student perceptions regarding the relevance of this type of knowledge for their chosen major or career, particularly in the anthropology and chemistry cases (NA1, NA3, NC1, NC2). In these two cases, difficulties with using features of the computer systems (NC3, NC4) and their malfunction (NA6, NC3,

\begin{tabular}{ll} 
Positive aspects & Negative aspects \\
\hline Anthropology & Anthropology \\
PA1: "New computer software and new info. about maps & NA1: "Not relevant to career/major" \\
development" & NA2: "Material itself was very dry" \\
PA2: "Saw how computers can be used to trace human & NA3: "I am just not interested in this" \\
history" & NA4: "Doesn't seem to be applicable to other fields of \\
PA3: "Well organized lectures and labs" & study" \\
& NA5: "Needs to be generalized, show how applied to a \\
& wide range of fields" \\
& NA6: "Computer glitches that need to be worked out" \\
Sociology & Sociology \\
PS1: "Illustrated IT and gave me an idea of what IT can & NS1: "Did not sound interesting at all" \\
do \& IT's potential" & NS2: "It was somewhat boring and slow" \\
PS2: "Good use of data to find trends" & NS3: "Calculations were tedious" \\
PS3: "Informative" & NS4: "Complicated math" \\
PS4: "Ease of using Excel" & NS5: "Accountant like dullness, need more dynamic in- \\
PS5: "Learn the job market that is arising \& the way it & volvement from class" \\
may be in future" & \\
PS6: "It showed us the future of the job industry" & \\
Chemistry & Chemistry \\
PC1: "Amazed at how computers work to make difficult & NC1: "Case study did not relate to me leaving me clue- \\
tasks easier" & less" \\
PC2: "Made me aware of IT courses to stay away from" & NC2: "Irrelevance to major, satisfies no requirement, \\
PC3: "Liked working with Alchemy in the lab" & waste of time" \\
PC4: "Interesting to use Alchemy in relation with Inter- & NC3: "Waiting long for results and didn't know what to \\
net" & do with them" \\
& NC4: "Software was somewhat confusing" \\
& NC5: "Computers were slow" \\
&
\end{tabular}

Table 5: Main positive and negative aspects of the cases (In the students' own words) 
NC5) were also mentioned as negative aspects, even though students also reported enjoying working with the systems (PA1, PC3, PC4). While in the sociology case the computer system was seen as simple and easy to use (PS4), and no malfunctions were reported, the case itself was seen as using complex and "boring" concepts and methods (NS1, NS2, NS3, NS4, NS5).

\section{Discussion and Conclusion}

The data analysis suggests that the case studies had a positive impact on how students, who are not particularly interested in IT, perceive IT in general, and its application to complex and specialized tasks. However, it should be noted that this is a small sample size and problems with presenting two of the case studies affected students' perceptions. While the students generally reported that they learned from the case studies, the results also suggest that the case studies did not have a positive impact on the students' willingness to pursue an IT career or take other IT courses. One possible explanation for this, based in part on GOMS theory (Card et al., 1983) and cognitive flexibility theory (Spiro and Jehng, 1990; Spiro et al., 1992), is that subjecting non-majors to complex and specialized IT applications increases their "respect" for IT's potential, but does not help them gain confidence about being specialized IT users themselves. It is quite possible that the degree of technological and domain complexity in the case studies led the students to believe that using IT was too difficult for the tasks that they may have to accomplish in their chosen fields of study. In fact these observations led us to re-design aspects of the case studies when we created the actual computer fluency course. In particular we attempted to "ground" the case studies by providing real-life examples and incorporating "hands-on" lab experiences to complement each topic.

The correlation analysis suggests a strong positive correlation between the degree of students' interest in IT prior to taking the case studies, and their degree of interest in taking more IT courses in the future and pursuing an IT career. This is an interesting and important pattern since, if this correlation were negative, the case studies would be turning off previously interested students. Another trend is a strong positive correlation between the students' perception of the degree to which they had learned something about specialized IT applications and about IT issues in general. That is, the specialized case studies seem to have served the purpose of advancing the students' general understanding of IT issues.

The results of the qualitative analysis reinforce the findings above and, when looked at from a theoretical perspective, also provide hints on possible explanations for those findings and ways to improve the overall impact of the cases on students' perceptions and learning. For instance, the negative student perceptions regarding the relevance of this type of course for their chosen major or career, which are consistent with the principles of meaningfulness from minimalist theory (Carroll, 1990; 1998) and immediate relevance from andragogy theory (Knowles, 1975; 1984, 1984b), suggest that this type of course may not be appropriate as a "core" (i.e., non-elective) course. Unless the course can be more explicitly coupled with tasks in their major the students are unlikely to make the connection of how these concepts and skills can be useful to them.

The occurrence of computer problems was due to the complexity of the anthropology and chemistry computer systems and related installation problems, which, given their nature, should be relatively easy to eliminate in future course offerings. Identifying these types of problems was one of the advantages of being able to test the prototype case studies before actually teaching the course. The perceived complexity of the topics can be addressed in three main ways: (a) by dedicating more time to the demonstration of the computer systems; (b) by spending more time discussing how the topics relate to the concepts and theory discussed in the lectures, and (c) by shaping the course so that it is more closely aligned with the students' interests (and possibly, major).

A potentially problematic area in studies of this kind is that of evaluation, so our findings should be seen as preliminary and exploratory. Certain variables, whose effects can be expected to surface in situations 
involving teaching and learning, can add uncertainty to findings based on assessments of the long-term impact of the course on students. For example, a longitudinal analysis may reveal that the expected longterm impact of our course on non-majors' interest in IT topics cannot be clearly traced back to the course, because (it may be the case that) only students who already had an interest in IT topics took the course. While it would be extremely beneficial to follow the students use of these tools over a period of a few years such an assessment was not a part of this study. However, longitudinal studies of this type would certainly be valuable.

The development of new domain-specific case studies is an important area of further research in connection with this study. Another area in which problems may potentially arise is in the development of the domain-specific case studies, where the views of the domain experts about what is an interesting (or even acceptable) topic may not match that of students outside the experts' specific disciplines. For example, a student majoring in history may see a case study on computer applications in molecular biology research as too "dry" or specialized to be meaningful. This can be addressed in three main ways: (a) by providing clear descriptions of the cases addressed by the course; (b) by making it an elective course; and (c) by creating different versions of the course, addressing cases that are relevant to key disciplines, and targeting those versions to specific majors.

Our hope is that other instructors and researchers will use the results discussed in this paper and the framework presented by Aiken et al. (2000) to build courses with similar goals and objectives. For example, one might build a computer fluency course for students in specific fields, such as business, education, social sciences, etc. drawing on specific case studies from the field. This might also provide a good opportunity for trying new ideas and for team teaching with different instructors including case studies from their own research area (i.e. accounting, finance, statistics).

\section{References}

Aiken, B., Kock, N. and Mandviwalla, M. (2000), Fluency in Information Technology: A Second Course for non-CIS Majors, Proceedings of SIGCSE 00 Conference, The Association for Computing Machinery, New York, NY, pp. 280-284.

Card, S., Moran, T. and Newell, A. (1983), The Psychology of Human-Computer Interaction, Erlbaum, Hillsdale, NJ.

Carroll, J.M. (1990), The Nurnberg Funnel, MIT Press, Cambridge, MA.

Carroll, J.M. (1998), Minimalism Beyond the Nurnberg Funnel, MIT Press, Cambridge, MA.

Ernst, G. and Newell, A. (1969), GPS: A Case Study in Generality and Problem Solving, Academic Press, New York, NY.

Gurwitz, C. (1998), "The Internet as a Motivating Theme in a Math/Computer Core Course for Nonmajors", Proceedings of SIGCSE 98, The Association for Computing Machinery, New York, NY, pp. 68-72.

Joyce, D. (1998), "The Computer as a Problem Solving Tool: A Unifying View for a Non-Majors Course", Proceedings of SIGCSE 98, The Association for Computing Machinery, New York, NY, pp. 63-67.

Khosrwopour, M. (Ed) (1998), Effective Utilization and Management of Emerging Information Technologies, Idea Group Publishing, Hershey, PA.

Kock, N., Aiken, R. and Sandas, C. (2002), Using Complex IT in Specific Domains: Developing and Assessing a Course for Non-Majors, IEEE Transactions on Education, V.45, No.1, pp. 50-57.

Knowles, M. (1975), Self-Directed Learning, Follet, Chicago, IL.

Knowles, M. (1984), The Adult Learner: A Neglected Species, Gulf Publishing, Houston, TX.

Knowles, M. (1984b), Andragogy in Action, Jossey-Bass, San Francisco, CA.

Laudon K.C. and Laudon, J.P. (1999), Management Information Systems: Organization and Technology in the Networked Enterprise, Prentice Hall, Englewood Cliffs, N.J.

Marks, J., Freeman, W. and Leitner, H. (2001), Teaching Applied Computing without Programming: A Case-Based Introductory Course for General Education, Proceedings of SIGCSE 01 Conference, The Association for Computing Machinery, New York, NY, pp. $80-84$. 
Newell, A. and Simon, H. (1972), Human Problem Solving, Prentice-Hall, Englewood Cliffs, NJ.

Papert, S. (1980). Mindstorms: Children, Computers and Powerful Ideas, Basic Books, New York, NY.

Papert, S. (1993), Childrens' Machines: Rethinking Schools in the Age of the Computer, Basic Books New York, NY.

Pask, G. (1975), Conversation, Cognition, and Learning, Elsevier, New York, NY.

Salomon, G. (1979), Interaction of Media, Cognition, and Learning, Jossey-Bass, San Francisco, CA.

Salomon, G. (1981), Communication and Education, Sage, Beverly Hills, CA.

Salomon, G., Perkins, D. and Globerson, T. (1991), Partners in Cognition: Extending Human Intelligence with Intelligent Technologies, Educational Researcher, V.20, No.4, pp. 2-9.

Schneider, G.M. (1999), Computational Science as an Interdisciplinary Bridge, Proceedings of SIGCSE 99, The Association for Computing Machinery, New York, NY, pp. 141-145.

Siegel, S. and Castellan, N.J. (1998), Nonparametric Statistics for the Behavioral Sciences, McGraw-Hill, Boston, MA.

Spiro, R.J. and Jehng, J. (1990), Cognitive Flexibility and Hypertext: Theory and Technology for the Non-linear and Multidimensional Traversal of Complex Subject Matter, Nix, D. and Spiro, R. (Eds.), Cognition, Education, and Multimedia, Erlbaum, Hillsdale, NJ.

Spiro, R.J., Feltovich, P.J., Jacobson, M.J. and Coulson, R.L. (1992), Cognitive Flexibility, Constructivism and Hypertext: Random Access Instruction for Advanced Knowledge Acquisition in Ill-structured Domains, Duffy, T. and Jonassen, D. (Eds.), Constructivism and the Technology of Instruction, Erlbaum, Hillsdale, NJ.

Toffler, A. and Toffler, H. (1995), Creating a New Civilization: The Politics of the Third Wave, Turner Publications, New York, NY.

Van Der Meij, H. and Carroll, J.M. (1995), Principles and Heuristics for Designing Minimalist Instruction, Technical Communications, V.42, No.2, pp. 243-261.

\section{Appendix A: Case Study Descriptions}

\section{(1) Modeling human behavior over time and space: Deforestation in tropical America}

This case study examines the expansion of tropical forest farmers and the accompanying deforestation in Central Panama during the time period from 9000 to 2000 years ago through the use of simulations carried out in a GIS (Geographic Information Systems) environment.

\section{(2) Occupational and age cohort consequences of the industrial transfor- mation, 1980-1990}

This case study examines and evaluates possible explanations for the shifts in occupational distribution that have occurred in the United States between 1980 and 1990. Data used in this case study are the one percent Public Use Sample of the 1980 and 1990 Censuses. The principal software tool used is MS Excel.

\section{(3) Exploring structures of organic molecules by computational methods}

This case study examines methods for correlating measured physical properties of simple organic molecules with their structures. The calculations are performed with the aid of a commercially available software for molecular design called Alchemy. 


\section{Appendix B: Questionnaire used in pilot implementation}

For questions 1-9, the following scale was used in the first part of the questions:

( ) Strongly disagree ( ) Disagree somewhat ( ) Neither disagree or agree ( ) Agree somewhat ( ) Strongly agree

\section{Demographics:}

Sex: ( ) Male ( ) Female

Age:

First language: ( ) English ( ) Other

\section{Attitudes toward IT prior to taking the course}

1. I already had a very good knowledge of Information Technology (IT) prior to taking this course.

2. I intended to take as many IT courses as possible in college prior to taking this course.

3. I was generally very attracted to IT issues prior to taking this course.

\section{Case study impact on attitudes toward IT}

4. The case study made me feel like I should take more IT courses in the future, even if I don't pursue a career in IT. Why? (Explain your answer)

5. The case study made me feel like I should pursue an IT career. Why? (Explain your answer)

6. The case study improved my perception of IT's potential for solving complex tasks. Why? (Explain your answer)

7. The case study improved my general perception of IT. Why? (Explain your answer)

\section{Case study impact on IT knowledge}

8. I learned a lot from this case study about specialized IT applications. Why? (Explain your answer)

9. I learned a lot from this case study about IT issues in general. Why? (Explain your answer)

\section{Positive and negative aspects of the case study:}

10. What were the main positive aspects of this case study?

11. What were the main negative aspects of this case study? 


\section{Appendix C: Correlation tables}

\section{Anthropology}

Correlations

\begin{tabular}{|c|c|c|c|c|c|c|c|c|c|c|c|}
\hline & & & Q1 & Q2 & Q3 & Q4 & Q5 & Q6 & Q7 & Q8 & Q9 \\
\hline \multirow[t]{27}{*}{ Spearman's rho } & \multirow[t]{3}{*}{ Q1 } & Correlation Coefficient & 1.000 & .403 & $.835^{* *}$ & .223 & .390 & .447 & .100 & -.046 & -.180 \\
\hline & & Sig. (2-tailed) & & .194 & .001 & .487 & .210 & .145 & .757 & .900 & .619 \\
\hline & & $\mathrm{N}$ & 12 & 12 & 12 & 12 & 12 & 12 & 12 & 10 & 10 \\
\hline & \multirow[t]{3}{*}{ Q2 } & Correlation Coefficient & .403 & 1.000 & .698 * & .368 & .856 ** & -.159 & .335 & .358 & .289 \\
\hline & & Sig. (2-tailed) & .194 & . & .012 & .240 & .000 & .622 & .287 & .309 & .418 \\
\hline & & $\mathrm{N}$ & 12 & 12 & 12 & 12 & 12 & 12 & 12 & 10 & 10 \\
\hline & \multirow[t]{3}{*}{ Q3 } & Correlation Coefficient & $.835^{* *}$ & $.698^{*}$ & 1.000 & $.600 *$ & .736 ** & .448 & .230 & .000 & -.246 \\
\hline & & Sig. (2-tailed) & .001 & .012 & . & .039 & .006 & .144 & .472 & 1.000 & .493 \\
\hline & & $\mathrm{N}$ & 12 & 12 & 12 & 12 & 12 & 12 & 12 & 10 & 10 \\
\hline & \multirow[t]{3}{*}{ Q4 } & Correlation Coefficient & .223 & .368 & $.600 *$ & 1.000 & .568 & $.663 *$ & .246 & -.219 & -.613 \\
\hline & & Sig. (2-tailed) & .487 & .240 & .039 & . & .054 & .019 & .441 & .543 & .060 \\
\hline & & $\mathrm{N}$ & 12 & 12 & 12 & 12 & 12 & 12 & 12 & 10 & 10 \\
\hline & \multirow[t]{3}{*}{ Q5 } & Correlation Coefficient & .390 & $.856 * *$ & $.736^{* *}$ & .568 & 1.000 & -.018 & .253 & -.022 & -.121 \\
\hline & & Sig. (2-tailed) & .210 & .000 & .006 & .054 & . & .956 & .427 & .952 & .739 \\
\hline & & $\mathrm{N}$ & 12 & 12 & 12 & 12 & 12 & 12 & 12 & 10 & 10 \\
\hline & \multirow[t]{3}{*}{ Q6 } & Correlation Coefficient & .447 & -.159 & .448 & $.663^{*}$ & -.018 & 1.000 & .153 & -.126 & -.523 \\
\hline & & Sig. (2-tailed) & .145 & .622 & .144 & .019 & .956 & . & .635 & .728 & .121 \\
\hline & & $\mathrm{N}$ & 12 & 12 & 12 & 12 & 12 & 12 & 12 & 10 & 10 \\
\hline & \multirow[t]{3}{*}{ Q7 } & Correlation Coefficient & .100 & .335 & .230 & .246 & .253 & .153 & 1.000 & .615 & .254 \\
\hline & & Sig. (2-tailed) & .757 & .287 & .472 & .441 & .427 & .635 & . & .058 & .480 \\
\hline & & $\mathrm{N}$ & 12 & 12 & 12 & 12 & 12 & 12 & 12 & 10 & 10 \\
\hline & \multirow[t]{3}{*}{ Q8 } & Correlation Coefficient & -.046 & .358 & .000 & -.219 & -.022 & -.126 & .615 & 1.000 & .848 * \\
\hline & & Sig. (2-tailed) & .900 & .309 & 1.000 & .543 & .952 & .728 & .058 & . & .002 \\
\hline & & $\mathrm{N}$ & 10 & 10 & 10 & 10 & 10 & 10 & 10 & 10 & 10 \\
\hline & \multirow[t]{3}{*}{ Q9 } & Correlation Coefficient & -.180 & .289 & -.246 & -.613 & -.121 & -.523 & .254 & .848 ** & 1.000 \\
\hline & & Sig. (2-tailed) & .619 & .418 & .493 & .060 & .739 & .121 & .480 & .002 & . \\
\hline & & $\mathrm{N}$ & 10 & 10 & 10 & 10 & 10 & 10 & 10 & 10 & 10 \\
\hline
\end{tabular}

${ }^{* *}$. Correlation is significant at the .01 level (2-

${ }^{*}$. Correlation is significant at the .05 level (2- 


\section{Sociology}

Correlations

\begin{tabular}{|c|c|c|c|c|c|c|c|c|c|c|c|}
\hline & & & Q1 & Q2 & Q3 & Q4 & Q5 & Q6 & Q7 & Q8 & Q9 \\
\hline \multirow[t]{26}{*}{ Spearman's rho } & \multirow[t]{3}{*}{ Q1 } & Correlation Coefficient & 1.000 & $.647^{\star \star}$ & $.723^{\star \star}$ & $.491^{*}$ & .017 & $.501^{\star}$ & $.552^{*}$ & -.168 & .311 \\
\hline & & Sig. (2-tailed) & & .004 & .001 & .038 & .946 & .034 & .017 & .506 & .210 \\
\hline & & $\mathrm{N}$ & 18 & 18 & 17 & 18 & 18 & 18 & 18 & 18 & 18 \\
\hline & \multirow[t]{3}{*}{ Q2 } & Correlation Coefficient & $.647^{\star \star}$ & 1.000 & $.914^{\star \star}$ & $.711^{\star \star}$ & .393 & .331 & $.504^{\star}$ & .060 & $.557^{\star}$ \\
\hline & & Sig. (2-tailed) & .004 & & .000 & .001 & .107 & .180 & .033 & .814 & .016 \\
\hline & & $\mathrm{N}$ & 18 & 18 & 17 & 18 & 18 & 18 & 18 & 18 & 18 \\
\hline & \multirow[t]{3}{*}{ Q3 } & Correlation Coefficient & $.723^{\star \star}$ & $.914^{\star \star}$ & 1.000 & $.860^{\star *}$ & .462 & .402 & $.496^{\star}$ & .037 & .460 \\
\hline & & Sig. (2-tailed) & .001 & .000 & . & .000 & .062 & .110 & .043 & .888 & .063 \\
\hline & & $\mathrm{N}$ & 17 & 17 & 17 & 17 & 17 & 17 & 17 & 17 & 17 \\
\hline & \multirow[t]{3}{*}{ Q4 } & Correlation Coefficient & $.491^{*}$ & $.711^{\star \star}$ & $.860^{\star \star *}$ & 1.000 & $.526^{*}$ & .230 & .216 & .347 & .357 \\
\hline & & Sig. (2-tailed) & .038 & .001 & .000 & & .025 & .358 & .390 & .158 & .146 \\
\hline & & $\mathrm{N}$ & 18 & 18 & 17 & 18 & 18 & 18 & 18 & 18 & 18 \\
\hline & \multirow[t]{3}{*}{ Q5 } & Correlation Coefficient & .017 & .393 & .462 & $.526^{\star}$ & 1.000 & -.441 & .256 & .133 & .000 \\
\hline & & Sig. (2-tailed) & .946 & .107 & .062 & .025 & . & .067 & .305 & .598 & 1.000 \\
\hline & & $\mathrm{N}$ & 18 & 18 & 17 & 18 & 18 & 18 & 18 & 18 & 18 \\
\hline & \multirow[t]{2}{*}{ Q6 } & Correlation Coefficient & $.501^{*}$ & .331 & .402 & .230 & -.441 & 1.000 & .440 & .044 & .421 \\
\hline & & $\mathrm{N}$ & 18 & 18 & 17 & 18 & 18 & 18 & 18 & 18 & 18 \\
\hline & \multirow[t]{3}{*}{ Q7 } & Correlation Coefficient & $.552^{*}$ & $.504^{\star}$ & $.496^{\star}$ & .216 & .256 & .440 & 1.000 & -.176 & .416 \\
\hline & & Sig. (2-tailed) & .017 & .033 & .043 & .390 & .305 & .067 & . & .484 & .086 \\
\hline & & $\mathrm{N}$ & 18 & 18 & 17 & 18 & 18 & 18 & 18 & 18 & 18 \\
\hline & \multirow[t]{3}{*}{ Q8 } & Correlation Coefficient & -.168 & .060 & .037 & .347 & .133 & .044 & -.176 & 1.000 & .322 \\
\hline & & Sig. (2-tailed) & .506 & .814 & .888 & .158 & .598 & .862 & .484 & . & .192 \\
\hline & & $\mathrm{N}$ & 18 & 18 & 17 & 18 & 18 & 18 & 18 & 18 & 18 \\
\hline & \multirow[t]{3}{*}{ Q9 } & Correlation Coefficient & .311 & $.557^{\star}$ & .460 & .357 & .000 & .421 & .416 & .322 & 1.000 \\
\hline & & Sig. (2-tailed) & .210 & .016 & .063 & .146 & 1.000 & .082 & .086 & .192 & . \\
\hline & & $\mathrm{N}$ & 18 & 18 & 17 & 18 & 18 & 18 & 18 & 18 & 18 \\
\hline
\end{tabular}

${ }^{* *}$. Correlation is significant at the .01 level (2-tailed)

*. Correlation is significant at the .05 level (2-tailed).

\section{Chemistry}

Correlations

\begin{tabular}{|c|c|c|c|c|c|c|c|c|c|c|c|}
\hline & & & Q1 & Q2 & Q3 & Q4 & Q5 & Q6 & Q7 & Q8 & Q9 \\
\hline \multirow[t]{25}{*}{ Spearman's rho } & \multirow[t]{3}{*}{ Q1 } & Correlation Coefficient & 1.000 & .201 & .393 & .458 & .233 & .402 & .143 & .026 & -.340 \\
\hline & & Sig. (2-tailed) & & .491 & .165 & .099 & .423 & .173 & .642 & .933 & .256 \\
\hline & & $\mathrm{N}$ & 14 & 14 & 14 & 14 & 14 & 13 & 13 & 13 & 13 \\
\hline & \multirow[t]{3}{*}{ Q2 } & Correlation Coefficient & .201 & 1.000 & .411 & .481 & $.719^{\star \star}$ & .492 & .344 & .249 & .201 \\
\hline & & Sig. (2-tailed) & .491 & . & .145 & .081 & .004 & .088 & .250 & .412 & .511 \\
\hline & & $\mathrm{N}$ & 14 & 14 & 14 & 14 & 14 & 13 & 13 & 13 & 13 \\
\hline & \multirow[t]{3}{*}{ Q3 } & Correlation Coefficient & .393 & .411 & 1.000 & .392 & .435 & .400 & .387 & .337 & .110 \\
\hline & & Sig. (2-tailed) & .165 & .145 & . & .166 & .120 & .176 & .192 & .260 & .721 \\
\hline & & $\mathrm{N}$ & 14 & 14 & 14 & 14 & 14 & 13 & 13 & 13 & 13 \\
\hline & \multirow[t]{3}{*}{ Q4 } & Correlation Coefficient & .458 & .481 & .392 & 1.000 & $.616^{\star}$ & $.796^{\star \star}$ & $.595^{\star}$ & .474 & .260 \\
\hline & & Sig. (2-tailed) & .099 & .081 & .166 & & .019 & .001 & .032 & .102 & .391 \\
\hline & & $\mathrm{N}$ & 14 & 14 & 14 & 14 & 14 & 13 & 13 & 13 & 13 \\
\hline & \multirow[t]{3}{*}{ Q5 } & Correlation Coefficient & .233 & $.719^{\star \star}$ & .435 & $.616^{*}$ & 1.000 & $.648^{\star}$ & .469 & .191 & $.588^{\star}$ \\
\hline & & Sig. (2-tailed) & .423 & .004 & .120 & .019 & . & .017 & .106 & .531 & .034 \\
\hline & & $\mathrm{N}$ & 14 & 14 & 14 & 14 & 14 & 13 & 13 & 13 & 13 \\
\hline & Q6 & Correlation Coefficient & .402 & .492 & .400 & $.796^{* *}$ & $.648^{*}$ & 1.000 & $.679^{*}$ & $.682^{*}$ & .278 \\
\hline & \multirow[t]{3}{*}{ Q7 } & Correlation Coefficient & .143 & .344 & .387 & $.595^{\star}$ & .469 & $.679^{\star}$ & 1.000 & $.640^{*}$ & .322 \\
\hline & & Sig. (2-tailed) & .642 & .250 & .192 & .032 & .106 & .011 & $\cdot$ & .018 & .307 \\
\hline & & $\mathrm{N}$ & 13 & 13 & 13 & 13 & 13 & 13 & 13 & 13 & 12 \\
\hline & \multirow[t]{3}{*}{ Q8 } & Correlation Coefficient & .026 & .249 & .337 & .474 & .191 & $.682^{*}$ & $.640^{*}$ & 1.000 & .261 \\
\hline & & Sig. (2-tailed) & .933 & .412 & .260 & .102 & .531 & .010 & .018 & . & .413 \\
\hline & & $\mathrm{N}$ & 13 & 13 & 13 & 13 & 13 & 13 & 13 & 13 & 12 \\
\hline & \multirow[t]{3}{*}{ Q9 } & Correlation Coefficient & -.340 & .201 & .110 & .260 & $.588^{\star}$ & .278 & .322 & .261 & 1.000 \\
\hline & & Sig. (2-tailed) & .256 & .511 & .721 & .391 & .034 & .382 & .307 & .413 &. \\
\hline & & $\mathrm{N}$ & 13 & 13 & 13 & 13 & 13 & 12 & 12 & 12 & 13 \\
\hline
\end{tabular}

${ }^{* \star}$. Correlation is significant at the .01 level (2-tailed)

*. Correlation is significant at the .05 level (2-tailed). 


\section{Biographies}

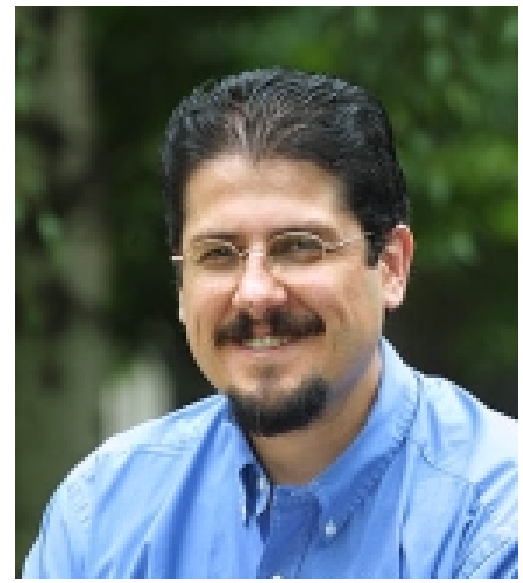

Ned Kock is Director of the E-Collaboration Research Center and CIGNA Research Fellow in the Fox School of Business and Management, Temple University, Philadelphia. He holds a PhD in information systems from the University of Waikato, New Zealand. He is interested in the impact of new IT teaching techniques and online learning tools. $\mathrm{He}$ is the author/co-author of three books, including Process Improvement and Organizational Learning: The Role of Collaboration Technologies and has authored articles published in a number of journals including Communications of the ACM, IEEE Transactions on Education, IEEE Transactions on Professional Communication, Information \& Management, Information Systems Journal, Information Technology \& People, Journal of Organizational Computing and Electronic Commerce, and Knowledge and Process Management.

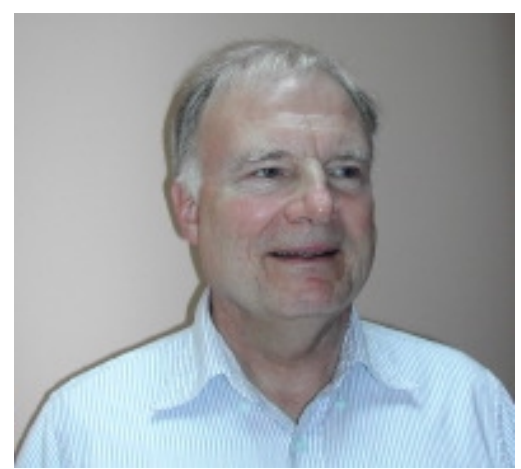

Robert Aiken is a Professor and Director of the Research Committee in the Computer and Information Sciences Department, Temple University. $\mathrm{He}$ is the (co-) author of three books as well as more than 80 articles in refereed journals and proceedings. His current research activity includes investigating the applicability of artificial intelligence models to education, developing collaborative learning systems and assessing the impact of technology in K-12 education. Dr. Aiken has consulted with UNESCO and OECD, and governmental organizations of several countries on developing and assessing graduate programs in Computer Science and strategic planning for the effective integration of computers into schools. He has received various awards including the ACM Outstanding Contribution to ACM Award (1996), the IEEE Computer Society Golden Core Award (1996), IFIP's highest award the Silver Core, (1992) and the ACM Special Interest Group on Computer Science Education (SIGCSE) Outstanding Contributions to Computer Science Education (1995) and Lifetime Service Awards (1999).

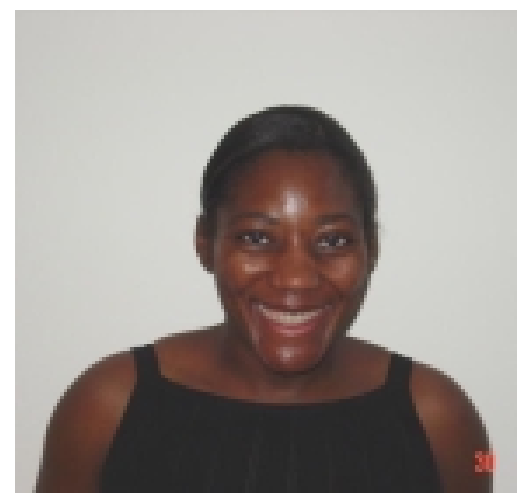

Cheryl Sandas received her M.S. computer and information sciences from Temple University and her B.S. in anthropology and psychology from Carnegie Mellon University. She is interested in the impact of technology on education. 